Osborne Clarke is one of Europe's most respected law firms and a UK leader in advising marketers on the legal issues affecting them. The firm's website, MarketingLaw.co.uk, has provided marketers with authoritative legal insights for over 10 years. Please send any queries regarding this column to Stephen Groom (Stephen.groom@ osborneclarke.com)

\section{Legal and Regulatory Update}

Journal of Direct, Data and Digital Marketing Practice (2014) 16, 61. doi:10.1057/dddmp.2014.55

\section{DMA clarifies ICO direct marketing guidance}

The ICO published detailed revised guidance on direct marketing in September 2013 to help organizations navigate the multitude of data protection laws which impact on this area.

\section{Direct marketing commission gets tough}

The DMC recommended that the DMA terminate Reactiv's membership and this is exactly what happened on 11 April 2014.

\section{Data controller/data processor distinction - New guidance}

The ICO has published its latest guidance on how to determine the difference between data controllers and data processors under the title: 'Data controllers and data processors: What the difference is and what the governance implications are'.

\section{Spam judgement against John Lewis highlights limits of soft opt-in and ICO guidance. But questions remain}

The first fully argued case in which damages have been claimed for breach of consent laws for unsolicited marketing email has ended in victory for the claimant.

\section{Dramatic increase proposed in maximum fines for breach of ad laws}

Companies may have to change their risk assessment procedure in relation to these offences, as the potential fines they could face for a breach of legislation will no longer be insignificant.

\section{EU data protection law reform latest}

By fair means or foul, a new version of the draft data protection regulation was published, or maybe leaked, on 30 June 2014.

The full text of these examples and cases can be read at www.marketinglaw.co.uk 